\title{
波動下の砂漣近傍の流れとエネルギー逸散
}

\section{FLOW NEAR SAND RIPPLES AND DISSIPATION OF WAVE ENERGY}

\author{
池田駿 介*・ 木崎 茂** ·石井修一*** ·栗林 俊一**** \\ By Syunsuke IKEDA, Shigeru KIZAKI, Shuichi ISHII and Shunichi KURIBAYASHI
}

\begin{abstract}
The present paper deals with vortex shedding from ripples and the associated wave energy dissipation. The circulation of the vortices is estimated with potential flow theory, applying Kutta's condition at the crest of ripples, which indicates that the circulation has a functional relationship with period of fluid oscillation, boundary layer thickness and fluid velocity at the edge of the boundary layer. The kinetic energy of the vortices is assumed to be dissipated to reduce the wave energy. A formula is derived under the assumption, and it is tested with wave flume experiment for which self-formed ripples are generated. A good correlation is found between the theory and the experimental result.

Keywords : dissipation, oscillatory flow, ripple, vortices, wave
\end{abstract}

\section{1. 序 論}

波動運動により誘起される砂漣の近傍には砂漣頂部か ら発生する組織的な渦が存在し，この渦が底質を巻き上 げることにより浮遊砂量が増大することが知られてい る. また，この渦が粘性逸散することにより波のエネル ギーの一部が失われる.このようなことから, 従来砂漣 の発生条件やその形状・スケール, 砂䡛近傍の流れ, 発 生する渦の強度やその挙動, 底質の巻き上げ量などにつ いて研究が行われている.

振動流によって形成される砂漣について系統的な実験 を行ったのは Bagnold ${ }^{1)}$ を嚆矢とするが，本間ら ${ }^{2), 3)}$ は 二次元造波水槽を用いて砂漣による浮遊砂に関する実験 を行い, 既往の砂漣形状に関するデー夕も含めて整理し, 砂漣の波高・波長と底質粒径および水理量（底面近傍の 水粒子の振幅）の間の関係式を提案している. また, Carstens ら ${ }^{4)}$ は振動流装置を用いた実験から得られた砂 漣に関するデータを報告している，最近ではこれまでに 得られたデー夕をもとに, 砂漣のスケールの予測法が

* 正会員 工博 埼玉大学教授 工学部建設基礎工学科 ( 污38 浦和市下大久保 255)

** 正会員 工修 (株)飛島建設

*** (株)サンコー・コンサルタント

**** 茨城県庁
Nielsen ${ }^{5}$ により提案されている.

砂漣近傍の流れの特徵は前述のように，砂漣頂部の前 後に形成される渦であるが，このような流れの構造を詳 細に検討したり，あるいはモデル化を行う研究も数多く 行われている. Horikawa ・ Watanabe ${ }^{6)}$ は水素気泡法を 用いて, 平坦床および砂漣モデル上の振動流境界層の詳

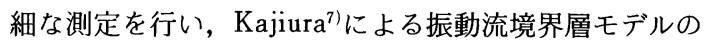
検討を行っている. Tunstall·Inman ${ }^{8)}$ は砂漣近傍の渦の 循環強度を可視化法により測定し，この強度が底面近傍 の水平方向流速と砂漣波高によって整理されることを示 した. さらに，この渦エネルギーと波の損失エネルギー を関連付けている. 沢本ら ${ }^{9) ~ 12) ~}$ 造波水路および空気振動流装置内に砂漣モデルを設置 し, 流速分布や乱れ分布を測定するとともに, 渦の循環 強度を測定している．また，渦をポテンシャル渦を用い てモデル化し, 渦層厚さの推算や渦度流束の集積として 求められる渦の循環強度の見積りを行い, これらを用い て浮遊砂の基準点濃度の予測法を提案している. Shibayama Horikawa ${ }^{13)}$ も渦に注目した研究を行ってい る. 波動下の砂漣近傍の流れをポリスチレン粒子により 可視化し, 渦の循環強度を読み取り, 渦度流束の集積と して得られる循環強度との比較を行っている. Du Toit·Sleath ${ }^{14)}$ は振動流中の砂漸モデル上の一方向流れ 
を測定し，Longuet-Higgins ${ }^{15)}$ はポテンシャル流理論に よる非粘性渦糸群モデルによって砂漣上の流れをモデル 化し，砂漣に作用する抗力を求めているが，ここでも渦 の循環強度は渦度流束の集積として求められている.す なわち, Prandtl の方法を用いて, 積分 $\Gamma_{n}=\int u_{n}^{2} d t / 2$ により循環値を求めている.ここに， $u_{n}$ は境界層外縁 の流速值である. 実際の計算では刻々の $u_{n}$ の值を用い, 数值積分することにより求められている.後述のように, 本研究ではKutta の条件を適用して循環を求めるので, 数值積分をする必要がなく，また explicit な形で循環の 予測が可能となる. 最近では砂漣や流れの非対称性を考 慮した研究 ${ }^{16)}, k-\varepsilon$ 乱流モデルを用いた流れ場の計算 も行われている17).

以上のように波動下や振動流中の砂漣近傍の流れにつ いては比較的多くの研究が行われ，渦の循環強度や挙動 などもしだいに把握されつつある. 本研究では, Longuet-Higgins のモデルに境界層を導入し，さらにKutta の条件を砂漣頂部に適用して渦の循環強度を見積る方法 を提案し，この方法によって予測される值を振動流中の 砂漣モデルおよび波動下の砂轋を用いて测定された值と 比較することによりモデルの妥当性を確かめる.さらに, この渦が粘性逸散することにより失われるエネルギーを 摩擦損失による分は除いた波のエネルギ一損失量と比較 し，両者の間の関係を調べる.

\section{2. 渦を伴う砂漣近傍の流れのモデル化}

シャープ・エッジ状の頂部をもつ砂漣近傍のポテン

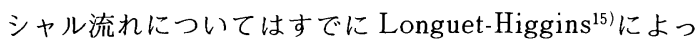
て解が得られているので, 本論文においてもその結果を 用いることとし，以後の理論展開において必要な程度に その概略について述べる.

Fig. 1 (a) のような砂漣の列を考える.このとき, 砂 漣の頂角を $\pi\left(1-2 / P_{r}\right)$ とする. この $z$ 面の砂漣形状 は次式により, Fig. 1(b) の $\zeta$ 面の $P_{r}$ 多角形に写像さ

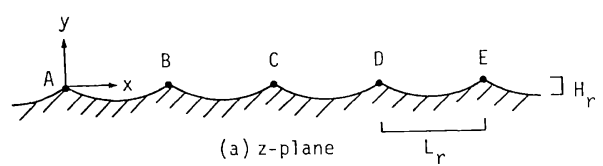

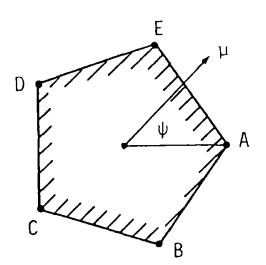

(b) $\zeta$-plane

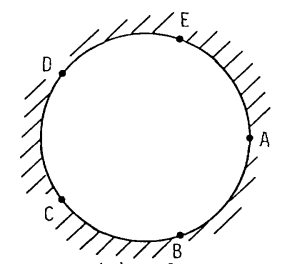

(c) w-plane
Fig. 1 Transformation of complex planes.
れる.

$$
\zeta=e^{-i k_{r} z}, k_{r} P_{r} L_{r}=2 \pi
$$

ここに， $k_{r}$ は砂漣の波数， $L_{r}$ は砂漸の波長である. $\zeta$ 面において境界を表わす式は以下のように与えられる。

$$
\mu \cos \left(\varphi-\varphi_{j}\right)=\cos \left(\pi / P_{r}\right), \quad \zeta=\mu e^{i \varphi} .
$$

ここに, $\mu, \varphi$ はそれぞれ $\zeta$ 平面上の半径方向と回転方 向の座標を表わし， $\varphi_{j}$ は多角形各辺の中点の座標を示 し, $\varphi_{j}=2 \pi(j-1 / 2) / P_{r}$ である $\left(j=1,2, \cdots P_{r}\right)$. 式 ( 1$)$, (2) 加ら $z$ 面における砂漣形状が求まり,

$$
k_{r}\left(y-y_{0}\right)=\ln \left[\sec k_{r}\left(x-x_{0}\right)\right],\left|k_{r}\left(x-x_{0}\right)\right| \leqq \frac{\pi}{P_{r}}
$$

となる.ここに， $x_{0}=-\varphi_{j} / k_{r}, y_{0}=\ln \left[\cos \left(\pi / P_{r}\right)\right] / k_{r}$ である.このとき, 砂漣波高 $H_{r}$ と波長 $L_{r}$ の比は次式 によって与えられる.

$$
\frac{H_{r}}{L_{r}}=\frac{\ln \left[\sec \left(\pi / P_{r}\right)\right]}{2 \pi / P_{r}}
$$

$\zeta$ 面の多角形外部の流れはSchwarz-Christoffel 変換に より, 次の写像関数を用いて $w$ 面の単位円の内部へ写 像される (Fig. 1(c)).

$$
\zeta=\zeta_{0}-K \int_{w_{0}}^{w} \frac{1}{w^{2}}\left(1-w^{P r}\right)^{2 / P r} d w
$$

ここに， $\zeta_{0}$ は定数， $K$ は写像のスケールを決定し， $P_{r}$ $=5$ (すなわち, 砂䡛の頂角が $108^{\circ}$ に相当する）のとき, $K=0.889$ である. また，この值のとき式（4）から $H_{r} / L_{r}=0.17$ となる. 砂漣から十分離れた点における 一様流速が $U$ であり, 砂漣間の位置 $z_{n}$ にある循環 $\Gamma_{n}$ をもつ渦の複素速度ポテンシャル $\chi$ は $w$ 面において

$$
\chi=\chi_{u}+\chi_{v}=\frac{U}{i k_{r}} \ln w+\sum_{n} \frac{\Gamma_{n}}{2 \pi i} \ln \frac{w^{P r}-w_{n}^{P_{r}}}{w^{P r}-\bar{w}_{n}^{P_{r}}} \cdots
$$

である、ここに， $\chi_{u} ， \chi_{v}$ はそれぞれ一様流，渦に対応 する複素速度ポテンシャルであり， $w_{n}, \bar{w}_{n}$ はそれぞれ $n$ 番目の渦, その鏡像渦の位置を表わす. 以上が Longuet-Higginsによって得られた複素速度ポテンシャ ルである。

砂漣背後に形成される組織的な剝離渦はせん断層内の 渦度が次々と非定常に放出され，これが集積することに より形成されると考えられる (Fig. 2).このような剝離 渦の循環や挙動を調べる方法として, 離散渦法が知られ ている ${ }^{18)}$. 本論文においてもこの方法を用いることとし， 㔀離点から放出される離散渦の循環とその放出時間間隔

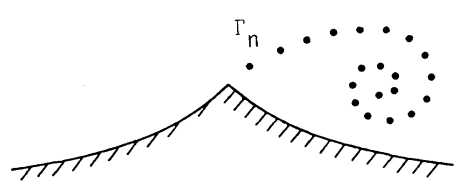

Fig. 2 Discrete vortex model. 
を見積り，その積分として組織的な剝離渦の循環を求め る.

まず，式（6）を用いて離散渦の循環を求める. 砂漸 のクレスト上 $\left(w=w_{c}\right)$ においてKuttaの条件,

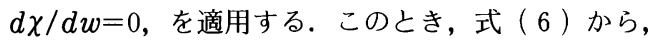

$$
\Gamma_{n}=-\frac{2 \pi U}{k_{r} P_{r}} w_{c}^{-P_{r}} \frac{\left(w_{c}^{P_{r}}-w_{n}^{P_{r}}\right)\left(w_{c}^{P_{r}}-\bar{w}_{n}^{P_{r}}\right)}{w_{n}^{P_{r}}-\bar{w}_{n}^{P_{r}}}+\alpha_{v}
$$

となる.ここに， $\alpha_{v}$ は $n$ 番目の渦以外の渦による寄与 分であり,

$$
\begin{aligned}
\alpha_{v}= & -\sum_{m=1}^{n-1} \Gamma_{m} \frac{w_{m}^{P_{r}}-\bar{w}_{m}^{P_{r}}}{\left(w_{c}^{P_{r}}-w_{m}^{P_{r}}\right)\left(w_{c}^{P_{r}}-\bar{w}_{m}^{P_{r}}\right)} \\
& \times \frac{\left(w_{c}^{P_{r}}-w_{n}^{P_{r}}\right)\left(w_{c}^{P_{r}}-\bar{w}_{n}^{P_{r}}\right)}{w_{n}^{p_{r}}-\bar{w}_{n}^{P_{r}}} \ldots \ldots \ldots \ldots
\end{aligned}
$$

である.ここで，砂漣のクレストの位置として Fig. 1(a) のA 点を選べば Fig. 1(c) において $w_{c}=1$ となり，さ らに $w_{n}$ にある渦に与える他の渦の影響は小さいとして 無視すれば式（7）の $\alpha_{v}$ はなくなり，式（7）は

$$
\Gamma_{n}=-\frac{2 \pi U}{k_{r} P_{r}} \frac{\left(1-w_{n}^{P_{r}}\right)\left(1-\bar{w}_{n}^{P_{r}}\right)}{w_{n}^{P_{r}}-\bar{w}_{n}^{P_{r}}}
$$

となる. $\alpha_{v}=0$ と置くことは砂漣頂部における流速に与 える他の渦の影響を無視することにほかならないが, 剝 離点付近の流速は砂漣背後にある渦よりもむしろ砂漣前 方の渦の影響をほとんど受けていない流れによって規定 されており，渦の影響は砂漣頂部ごく近傍にある渦のみ の寄与分を取り入れておけばよいと考えられる.

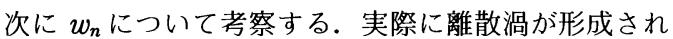
る位置は境界層内の渦度が渦として集中してくる点であ るので，境界層厚さ $\delta$ 程度境界から離れた点であると 考えられる．この位置を砂漣のクレストから $\delta$ 上方の 点とすると, $z$ 面において (Fig. 3参照)

$$
z_{n}=i \delta
$$

となる。この位置はら面では式（1）から

$$
\zeta_{n}=e^{k r \sigma}=1+\delta^{\prime}
$$

と表わされる. 次に $w$ 面においては式（5）において $w_{0}$ として A 点を選べば $w_{0}=\zeta_{0}=1$ となり, 式 $(5)$ お よび式（11）から

$$
\delta^{\prime}=-K \int_{1}^{w_{n}} \frac{1}{w^{2}}\left(1-w^{P r}\right)^{2 / P r} d w
$$

となる. $w$ 面においても $w_{n}$ の值は
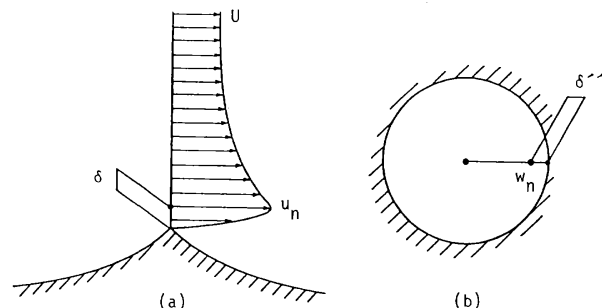

(a) 3 Definition of $\delta$ and $\delta^{\prime \prime}$

$$
w_{n}=1+\delta^{\prime \prime}
$$

とおけ (Fig. 3参照), また, 式 (12) 中の $w$ の值は 1 に近いので Taylor 展開し，積分すれば

$$
\delta^{\prime}=\frac{K}{2+P_{r}}\left(-P_{r} \delta^{\prime \prime}\right)^{\left(2+P_{r}\right) / P_{r}}
$$

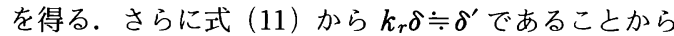

$$
\delta=\frac{K}{\left(2+P_{r}\right) k_{r}}\left(-P_{r} \delta^{\prime \prime}\right)^{\left(2+P_{r}\right) / P r} \text {. }
$$

または

$$
\delta^{\prime \prime}=-\frac{1}{P_{r}}\left[\frac{\left(2+P_{r}\right) k_{r} \delta}{K}\right]^{P_{r} /\left(2+P_{r}\right)}
$$

となる。

この $z_{n}$ における水平方向流速を $u_{n}$ とすれば (Fig. 3 参照), $u_{n}$ は式 (6) から

$$
\begin{aligned}
u_{n}= & R_{e}\left(\frac{d \chi}{d w} \frac{d w}{d z}\right)_{w=w_{n}}=R_{e}\left[\frac{\dot{w}_{n}}{w_{n}} \frac{U}{i k_{r}}+\dot{w}_{n}\right. \\
& \left.\times \sum_{j=1}^{n-1} \frac{\Gamma_{j}}{2 \pi i}\left(\frac{P_{r} w^{P_{r}-1}}{w^{P_{r}}-w_{j}^{P_{r}}}-\frac{P_{r} w^{P_{r}-1}}{w^{P_{r}}-\bar{w}_{j}^{P_{r}}}\right)_{w=w_{n}}\right] \cdots
\end{aligned}
$$

となる.ここに, $\dot{w}_{n}=(d w / d z)_{w=w_{n}}$ である.ここで, 前と同様に他の渦の影響は小さいとすれば, 式 (16) 中 の [ ]内第 2 項は無視でき, 結局, 境界層外縁の流速 $u_{n}$ を用いて表わされる $\Gamma_{n}$ の值は式（9）功

$$
\Gamma_{n}=-\frac{2 \pi u_{n}}{P_{r}} R_{e}\left(i \frac{w_{n}}{\dot{w}_{n}}\right) \frac{\left(1-w_{n}^{P_{r}}\right)\left(1-\bar{w}_{n}^{P_{r}}\right)}{w_{n}^{P_{r}}-\bar{w}_{n}^{P_{r}}}
$$

となる.ここで,

$$
\begin{aligned}
& w_{n}^{P_{r}} \fallingdotseq 1+P_{r} \delta^{\prime \prime}, \bar{w}_{n}^{P_{r}} \fallingdotseq 1-P_{r} \delta^{\prime \prime} \\
& \dot{w}_{n}=\frac{d w_{n}}{d z_{n}}=\frac{d\left(1+\delta^{\prime \prime}\right)}{d(i \delta)}=-\frac{1}{i} \frac{k_{r}}{K}\left[\frac{\left(2+P_{r}\right) k_{r} \delta}{K}\right]^{-2 /\left(2+P_{r}\right)}
\end{aligned}
$$

の関係を用い, 式 $(15 \cdot b)$ も援用して式 $(17)$ を変形 すれば, $\Gamma_{n}$ は

$$
\Gamma_{n}=-\frac{2+P_{r}}{P_{r}} \pi u_{n} \delta\left(1+\delta^{\prime \prime}\right)
$$

として与えられる. 式（18）により離散渦の循環が与え られる。

往復流半周期の間に砂漸の片側に形成される組織的な 剝離渦は半周期の間の離散渦の集積として表わせる. し たがって,この剥離渦の循環 $\Gamma$ は

$$
\Gamma=\int_{0}^{T / 2} f \Gamma_{n} d t=\frac{2+P_{r}}{P_{r}} \pi \int_{0}^{T / 2} f u_{n} \delta\left(1+\delta^{\prime \prime}\right) d t
$$

となる.ここに $f$ は離散渦の放出周波数, $T$ は周期で ある。

次に $f$ と $\delta$ につて物理的考察から決定する. 離散 渦は砂漸先端近傍のせん断層が不安定となり, 次々と渦 になることによって形成されると考えられる。このよう な現象を支配するパラメーターとして放出周波数 $f$, 代表流速 $U$, 代表スケール $\delta$ が挙げられ，これから誘 
導される無次元パラメーターはStrouhal 数, $s_{t}=$ $f \delta / U$ である.このような流れにおいて Strouhal 数が どのような值をとるかは明らかでないが, Strouhal 数 の值は形状が変化してもあまり変化せず, $s_{t}=0.1 \sim 0.3$ 程度の範囲に収まることが知られている ${ }^{19}$. 特に, 細長 い平板のような場合には $s_{t}=0.2$ となるので, この值を 採用することとし，いま考えているような流れでは渦は 片側のみから放出されるので, 結局 $f$ は $s_{t}=0.1$ ととっ た

$$
f=0.1 U / \delta
$$

\section{と表わされる.}

砂漣先端付近に形成される境界層の厚さ $\delta$ について は次のように考える. 平板上の振動流層流境界層では $\delta$ $\doteqdot 2 \sqrt{\nu T}$ と表わされる. また, 境界層内の速度分布が 比較的類似している粘性 Oseen 渦のコア領域の半径は $2.2 \sqrt{\nu t}$ であり ${ }^{20)}$, この值の半周期間の平均值をとれば, $\delta \doteqdot 1.04 \sqrt{\nu T}$ となる. 以上のように $\delta$ は $\sqrt{\nu T}$ に比例 すると考えられるが, この比例定数を検討するために, 砂漣モデル上で得られている流速分布の既往の測定デー 夕から $\delta$ を読み取り, 上述の值と比較したのが Table 1 である.これから, 粘性渦のコア領域の半径から得られ る値の方が実際の值をよく表わすことが知られる.した がって,

$$
\delta=1.04 \sqrt{\nu T}
$$

とする.

以上から, 式 (20), (21) を式（19）に代入し,さら に $U=\hat{U} \sin \omega t, u_{n}=\hat{u}_{n} \sin \omega t$ と置けば, $\Gamma$ の值は

$$
\Gamma=\frac{1}{40} \frac{2+P_{r}}{P_{r}} \pi\left(1+\delta^{\prime \prime}\right) T \lambda \hat{U}^{2}
$$

となる.ここに， 、は流速振幅， $\omega=2 \pi / T, \lambda=\hat{u}_{n} / \hat{U}$ である. 式 $(22)$ 中の $P_{r}$ は $5, \delta^{\prime \prime}$ は式 $(15 \cdot \mathrm{b})$ により 与えられる (式 $(15 \cdot b)$ 中の $K$ の值は 0.889 である). また, $\lambda$ の值は $\delta$ の大きさが式 (21) により与えられる ので, ポテンシャル流れを砂漣上で解き, 砂漸頂部上 $z$ $=i \delta$ における流速振幅 $\hat{u}_{n}$ を求め, これを $\hat{U} て ゙$ 割れば 求められる.ここでは, 簡単のために渦の寄与分を除い た值とした。 沢本・山口年の方法では循環は $\Gamma \propto k^{\prime 2} \hat{U}^{2}$ として求められ, $k^{\prime}$ の值は一定となっているが, 本方 法では砂漣の形状や境界層厚さの影響が明確となってい る.

Table 1 Value of $\delta$.

\begin{tabular}{|l|c|c|c|c|}
\hline \multirow{2}{*}{$T(s)$} & \multicolumn{3}{|c|}{$\delta(\mathrm{cm})$} & \multirow{3}{*}{ 文献 } \\
\cline { 2 - 3 } & \multicolumn{2}{|c|}{ 理論值 } & \multirow{2}{*}{ 実験值 } & \\
\cline { 2 - 3 } & $1.04 \sqrt{\nu T}$ & $2 \sqrt{\nu T}$ & & \\
\hline 6.4 & 1.02 & 1.96 & 0.89 & $11)$ \\
5.37 & 0.24 & 0.46 & 0.26 & $14)$ \\
\hline
\end{tabular}

\section{3. 砂漣による波のエネルギー逸散のモデル化}

以上のようにして形成された組織的な剥離渦が粘性逸 散することにより，波のエネルギーの減衰が生じると考 えられる.この值を見積るために，渦がもっている運動 エネルギーを求める.

このような剝離渦内の流速分布はOseen 渦型の流速 分布によってよく表わせることが知られており，その分 布形は以下のように表現される ${ }^{8), 20)}$.

$$
u_{\theta}=\frac{\Gamma}{2 \pi r}\left\{1-\exp \left[-1.25\left(\frac{r}{r_{a}}\right)^{2}\right]\right\} \cdots
$$

あるいは， $r=r_{a}$ で与えられる流速の最大値， $u_{\theta m}$, で 正規化すれば

$$
\frac{u_{\theta}}{u_{\theta m}}=1.4 \frac{r_{a}}{r}\left\{1-\exp \left[-1.25\left(\frac{r}{r_{a}}\right)^{2}\right]\right\}
$$

となる.ここに, $r$ は渦の中心からの半径である. 渦 のエネルギー $E_{v}$ は次式で与えられる.

$$
E_{v}=\frac{1}{2} \rho \int_{0}^{r_{\infty}} 2 \pi r u_{\theta}^{2} d r
$$

1 周期内には砂漣の両側にそれぞれ渦が形成されるの で, 1 周期の間の渦のエネルギー逸散量 $\bar{E}_{v}$ は, 式 (19), $(23 \cdot a)$ ，(24）を用いて

$$
\begin{aligned}
& \bar{E}_{v}=2 \int_{0}^{\tau / 2} f \frac{1}{2} \rho \int_{0}^{r_{\infty}} \frac{\Gamma_{n}}{2 \pi r} \\
& \cdot\left\{1-\exp \left[-1.25\left(\frac{r}{r_{a}}\right)^{2}\right]\right\}^{2} d r d t \\
& =\frac{\rho}{2 \pi} s_{0} \int_{0}^{T / 2} f \Gamma_{n}^{2} d t
\end{aligned}
$$

となる.ここに，

$$
s_{0}=\int_{0}^{r_{\infty}} \frac{1}{r}\left\{1-\exp \left[-1.25\left(\frac{r}{r_{a}}\right)^{2}\right]\right\}^{2} d r
$$

であり, 流速が最大流速の $0.1 \%$ となる半径を $r_{\infty}$ とと れば, $s_{0}=7.3$ となる. 式 (25) に式 (18), (20), (21) を代入して $\bar{E}_{v}$ は

$$
\bar{E}_{v}=\frac{1.04}{30}\left(\frac{2+P_{r}}{P_{r}}\right)^{2} \rho s_{0} \sqrt{\nu T}\left(1+\delta^{\prime \prime}\right)^{2} T \lambda^{2} \hat{U}^{3}
$$

となる.

渦による波のエネルギー逸散率を $P_{v}$ と置けば, 微小 振幅波に対し，

$$
\bar{E}_{v}=\frac{1}{8} \rho g H^{2} C_{G} P_{v}
$$

となる.ここに，H は波の波高， $C_{G}$ は群速度である. 式 (26)，(27）から $P_{v}$ が与えられるが，このとき微小

振幅波理論から得られる次の関係式

$$
\begin{aligned}
& \hat{U}=\frac{\pi H}{T} \frac{\cosh k\left(H_{r}+\delta\right)}{\sinh k h} . \\
& T=2 \pi\left(\frac{1}{g k} \operatorname{coth} k h\right)^{\frac{1}{2}} .
\end{aligned}
$$




$$
C_{G}=\frac{1}{2}\left(\frac{g}{k} \tanh k h\right)^{\frac{1}{2}}(1+2 k h \operatorname{cosech} 2 k h)
$$

を用いて変形すれば,

$$
\begin{aligned}
P_{v}= & \alpha \frac{\nu^{\frac{1}{2}}}{g^{\frac{1}{4}}} \frac{H}{L^{\frac{7}{4}}} \lambda^{2}\left(1+\delta^{\prime \prime}\right)^{2} \\
& \cdot \frac{\cosh ^{\frac{1}{4}} k h \cdot \cosh ^{3} k\left(H_{\tau}+\delta\right)}{\sinh ^{\frac{5}{4}} k h \cdot(2 k h+\sinh 2 k h)}
\end{aligned}
$$

となる.ここに， $k=2 \pi / L$ で波の波数， $L$ は波長であ り, $\alpha$ は

$$
\alpha=\frac{1}{30} 2^{\frac{17}{4}}\left(\frac{2+P_{r}}{P_{r}}\right)^{2} s_{0} \times 1.04 \pi^{\frac{9}{4}}
$$

である、これまで定義した值， $P_{r}=5, s_{0}=7.3$ ，を用 いると $\alpha=124$ となる. なお，式 $(28 \cdot a)$ から求められ る $\hat{U}$ は底面が平坦で砂轺がない場合の底面から $H_{r}+\delta$ の高さにおける流速振幅であり， $\hat{u}_{n}$ の值は砂漸がある 場合のポテンシャル流れの流速解で砂漣頂部から $\delta$ の 高さにおける流速をとり, これから $\lambda=\hat{u}_{n} / \hat{U}$ が求めら れる.また, 式 (29) 中の砂漣の波高 $H_{r}$ は本間・堀川 によって提案された次式を用いて見積ることができる.

$$
\frac{H_{r}}{L_{r}}=0.231\left(\frac{H_{r}}{A}\right)^{0.160}
$$

式（31）の $L_{r}$ は次式により与えられる.

$$
\begin{aligned}
& \frac{A}{L_{r}}=0.00234\left(\frac{\hat{U} A}{\nu}\right)^{0.674}: \text { 粒径 } 0.1 \sim 0.2 \mathrm{~mm} \cdots(32 \cdot \mathrm{a}) \\
& \frac{A}{L_{r}}=0.0985\left(\frac{\hat{U} A}{\nu}\right)^{0.289}: \text { 粒径 } 0.2 \sim 0.3 \mathrm{~mm} \cdots \cdots(32 \cdot \mathrm{b}) \\
& \frac{A}{L_{r}}=0.0253\left(\frac{\hat{U} A}{\nu}\right)^{0.409}: \text { 粒径 } 0.3 \sim 0.4 \mathrm{~mm} \cdots \cdot(32 \cdot \mathrm{c})
\end{aligned}
$$

\begin{tabular}{|c|c|c|}
\hline & $\begin{array}{l}\text { 造波水路実騟 } \\
\text { Case } \mathrm{Na} 2549\end{array}$ & 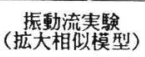 \\
\hline $\mathrm{Hr} / \mathrm{Lr}$ & 0.172 & 0.167 \\
\hline $\mathrm{Hr}(\mathrm{cm})$ & 0.63 & 5.0 \\
\hline $\operatorname{Lr}(\mathrm{cm})$ & 3.67 & 30.0 \\
\hline de $/ 2(\mathrm{~cm})$ & 2.52 & 20.0 \\
\hline$U(\mathrm{~cm} / \mathrm{s})$ & 15.8 & variable \\
\hline $\mathrm{T}(\mathrm{s})$ & 1.01 & variable \\
\hline $\mathrm{KC}=\mathrm{Lr} / \mathrm{TU}$ & 0.23 & 0.23 \\
\hline
\end{tabular}

ここに, $A$ は底面付近の水粒子の移動振幅である。な お上式を用いて後述の Table 4 に示されている砂漣形状

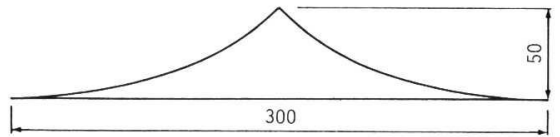

Fig. 4 Profile of ripple model (unit is $\mathrm{mm}$ ).

Table 2 Dimension of ripple model and comparison with self-formed ripple.
を予測したところ非常によく一致した。

\section{4. 実験および理論との比較}

実験は 2 種類に大別される. 1 つは管水路振動流実験 装置内に砂漣モデルを設置し，砂漣頂部から発生する剝 離渦を詳細に調べたものであり，他の 1 つは，二次元造 波水路を用いて砂漸を発生させ，そのときの波のエネル ギー逸散を測定したものである．実験は両方とも埼玉大 学水理工学実験室で行われた。

\section{a) 振動流実験}

振動流実験装置は $30 \mathrm{~cm} \times 30 \mathrm{~cm}$ の正方形断面, 長さ $13 \mathrm{~m}$ であり，長さ $210 \mathrm{~cm}$ の観測部を有している。流体

(水) はピストンによって駆動され, 振動流の最大片振 幅は $35 \mathrm{~cm}$, 周期は 1 秒から 20 秒の間で連続的に変化 させることができる. 砂漣モデルの形状は式 $(3)$ にっ て決定し, 波長 $L_{r}=30 \mathrm{~cm}$, 波高 $H_{r}=5 \mathrm{~cm}$ とした.こ の形状は $P_{r}=5$ の場合に相当する (Fig. 4)。この砂浅 モデルは観測部底面に 7 個連続して設置した。この砂漣 モデルと実砂漣との対応を調べるために, 後述の造波水 路実験において形成された砂漣形状と比較を行った.

Table 2 に造波水路実験 Run 2549 (Table 4 参照) 亡の 対応を示す.これから， $H_{r} / L_{r}$ の值はよく合っている ことが知られる.また，振動流実験においては一種の $K C$ 数, $L_{r} / T \hat{U}$ の值が造波水路で得られた值 0.23 亡一 致するように $T$ および $\hat{U}$ を変化させて行った (Table 2).

Table 3 Test condition of vortex measurement and condition for photographing.

\begin{tabular}{|c|r|c|c|c|c|}
\hline Case Na & $T(s)$ & $K C$ & $F($ 绞り) & S.S.(s) & Jマ/s \\
\hline 1 & 3 & 0.23 & 1.2 & $1 / 30$ & 1.3 \\
2 & 6 & 0.23 & 1.2 & $1 / 15$ & 2.5 \\
3 & 9 & 0.23 & 2.0 & $1 / 8$ & 2.5 \\
4 & 12 & 0.23 & 2.0 & $1 / 8$ & 2.5 \\
5 & 4 & 0.23 & 1.2 & $1 / 30$ & 2.5 \\
\hline
\end{tabular}

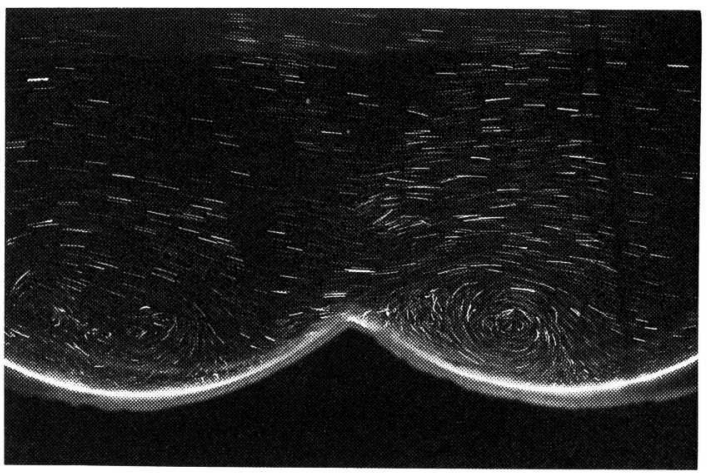

Fig. 5 An example of vortex behind the artificial ripple $(T=11.5 \mathrm{~s}, t / T=0.33)$. 
渦の可視化には比重 1.04 , 粒径が $0.3 \sim 0.5 \mathrm{~mm}$ の範 囲にあるポリスチレン粒子を用い，スライド・プロジェ クターからスリット光を照射し，これをモーター・ドラ イブ付 $35 \mathrm{~mm}$ カメラで Table 3 に示すような実験条件 の下で，連続写真を撮影した．このとき，撮影時と振動 流の位相関係を知るために, カメラのシャッタ一信号と 流体を駆動するピストンが 1 周期運動するごとの信号を オシログラフに記録した. 可視化実験はTable 3 に示す ように周期を 5 種類に変化させて行い, このとき $K C=$ 0.23 となるように振幅を変えた. Fig. 5 は可視化写真の 一例である。

このような写真から各位相における渦内の流速分布と 循環値を読み取るが，このとき砂漣近傍の渦は円形であ るとして, 渦の中心を決定してポリスチレン粒子の軌跡 長とカメラのシャッター・スピードより中心からの位置 $r$ における流速 $u_{\theta}$ を求める. また，これらの值を用い て循環値を次式により求める.

$$
\Gamma=2 \pi r u_{\theta}
$$

以上のようにして求められた渦内の流速分布と循環の分 布の一例（Case 3）を Fig. 6 に示す.これから渦内の流 速分布は式 $(23 \cdot b)$ で表わされるOseen 渦の分布形と よく一致し, また, 循環の分布も Oseen 渦の速度分布 から得られる循環の分布によってよく表現できることが 知られる. 他の Case についても同様であった。

このようにして測定されたコア域外縁近傍の最大循環 值を各位相ごとにプロットしたのが Fig. 7である.この

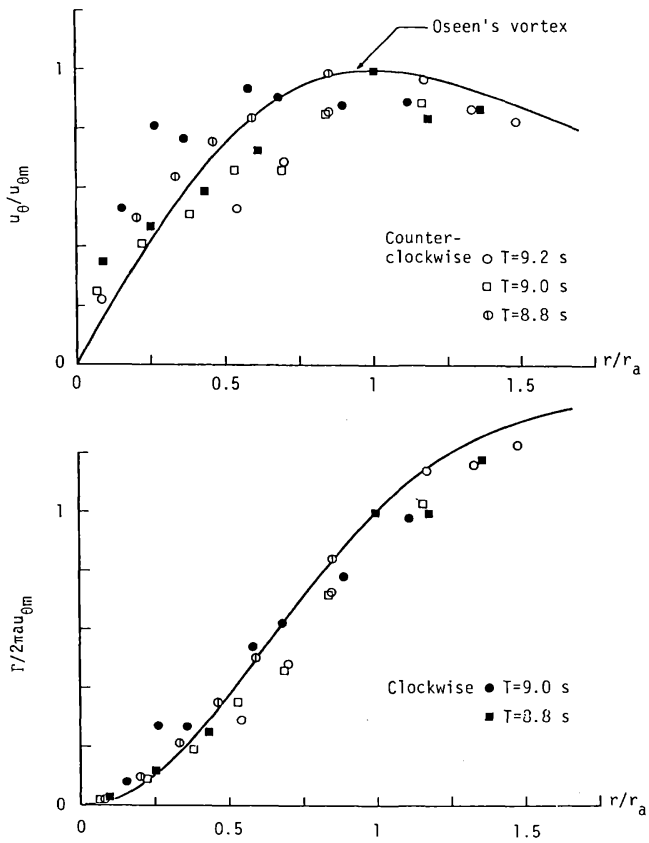

Fig. 6 Distributions of velocity and Circulation in vortices.
図から渦の循環の位相は主流流速の位相からいずれの Case についても遅れているが，1 周期内の循環の最大 值, $\Gamma_{\max }$ が発生する位相についてみると, 周期が長く
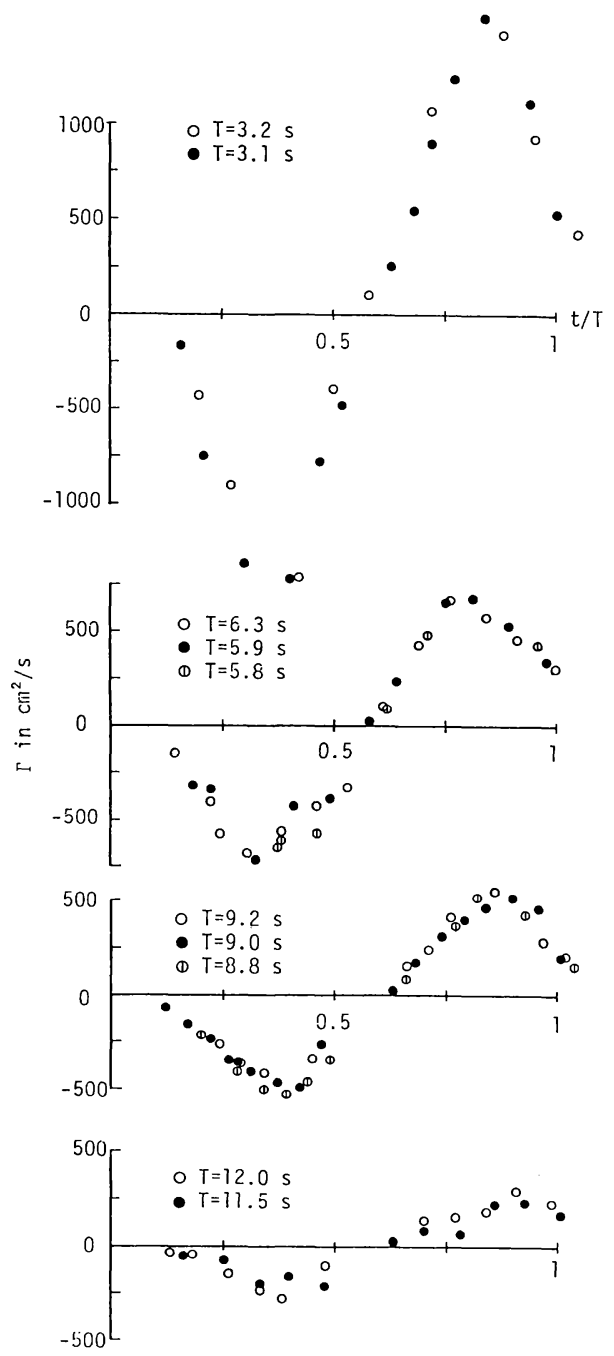

Fig. 7 Variation of circulation in a period.

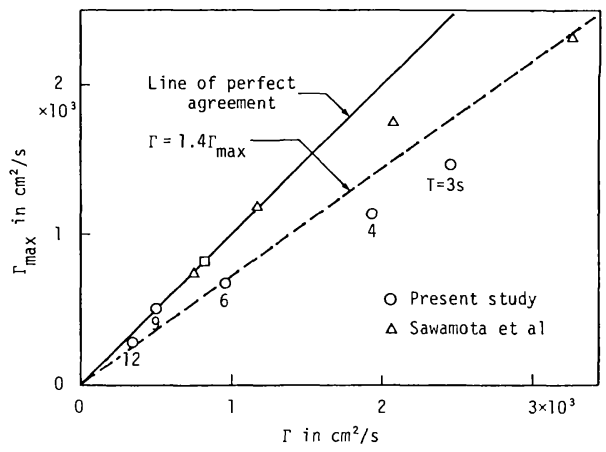

Fig. 8 Comparison of predicted circulation $(\Gamma)$ and observed maximum circulation in a period $\left(\Gamma_{\max }\right)$. 
なるほよ゙位相が遅れることが知られる，式 (22) から予 測される循環值は $\Gamma_{\max }$ に相当するので，この両者の比 較を Fig. 8 に示した．同図中には沢本ら ${ }^{11}$ によって測定 された振動流中に置かれた波型砂漸モデルから発生する 渦の循環值もプロットした．なお，彼らが用いた砂漣形 状は本研究で用いられた形状と異なるので, 式 (22) を 用いて循環值を予測するに際しては $\lambda=\hat{u}_{n} / \hat{U}$ の値とし て彼らが用いた砂漸形状に対するポテンシャル解から得 られる值を用いた。 Fig. 8 から理論值 $\Gamma$ と測定値 $\Gamma_{\max }$ はほぼ比例関係にあり，よい相関が認められるが，理論 値の方が実測值よりもやや大きい值（約 1.4 倍）を与え ている. しかも, 周期が短くなるほゼ（すなわち，本研 究では $K C=0.23$ と固定しているので, 流速が大きく なるほど）その傾向が強くなっている．この原因は流速 が増大するに従って境界層がしだいに乱流へ遷移し，式 （21）によって境界層厚さを見積ることが困難となり， それとともに $\hat{u}_{n}$ の值を実際の值よりも大きく予測する ためであると考えられる. Fig. 9 はこれを検討するため に往復流用の小型プロペラ流速計（直径 $3 \mathrm{~mm}$ ）を用い $\tau$, 流速分布を測定し，これから得られる境界層外縁の 実測流速值 $\hat{u}_{n}$ を用いて式 (22) から循環値 $\Gamma$ を見積り, これと実測値 $\Gamma_{\max }$ と比較したものである. 両者の対応 はきわめてよく，上述の仮説が正しいことが知られる. したがって，より広範囲にわたって循環値を正確に予測 するには，砂漣が存在する場における乱流境界層厚さや 流速分布を知る必要がある.

b）造波水路実験

実験にはFig. 10 に示されるように長さ $18 \mathrm{~m}$ ，幅 40 $\mathrm{cm}$, 深さ $70 \mathrm{~cm}$ の二次元造波水路を用いた。この水路 中央約 $8 \mathrm{~m}$ の区間は両面強化ガラス張となっている. 造波機の形式は単ヒンジ・フラッター型であり, 波型は 規則波である. 水路端にはフィルム屑を入れた消波装置 が設置されており, 後述の方法で反射率を測定したとこ ろ Fig. 11 に示されるように本実験で用いられた水深 $(20$ $\sim 30 \mathrm{~cm})$, 周期 $(1 \sim 1.5$ 秒) では反射率は $2 \sim 3 \%$ 以内 であることが知られる（実験条件の詳細は Table 4 を参 照のこと).

この造波水路の観察区間に中央粒径 $0.19 \mathrm{~mm}$ の豊浦 標準砂を長さ $8.5 \mathrm{~m}$, 厚さ $5 \mathrm{~cm}$ に敷きつめ, 砂漣を形 成させた. 砂漣が形成される前と後の波のエネルギー逸 散を求めるために, Fig. 10 に示すように砂漣区間 $4 \mathrm{~m}$ をはさんで前後に 2 台ずつ容量式波高計を設置し，波高 の測定を行った。この波高測定の結果を用いて, 砂漸が 十分に発達した段階のエネルギー逸散量から, 砂漣形成 前の平坦床におけるエネルギー逸散量を差し引き, 砂漣 によって形成される渦によるエネルギー逸散量を求め た。この波のエネルギー逸散量を求めるには, 砂漣が形

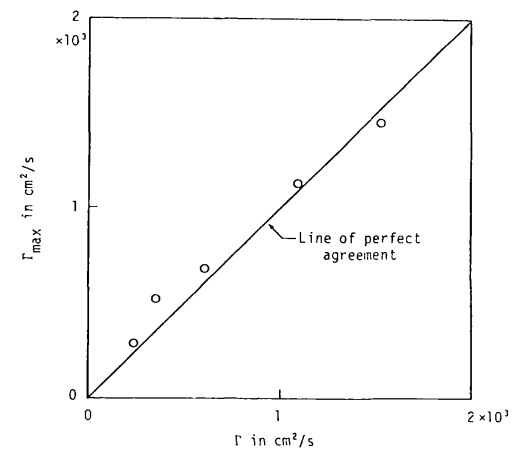

Fig. 9 Comparison of predicted $\Gamma$ using measured $\hat{u}_{n}$ and observed maximum circulation, $\Gamma_{\max }$.
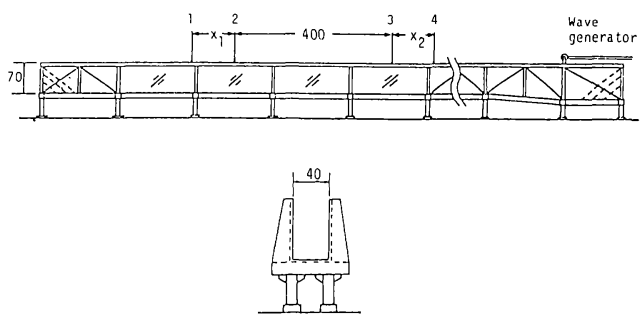

Fig. 10 Experimental apparatus of wave flume test (unit is $\mathrm{cm}$ ).

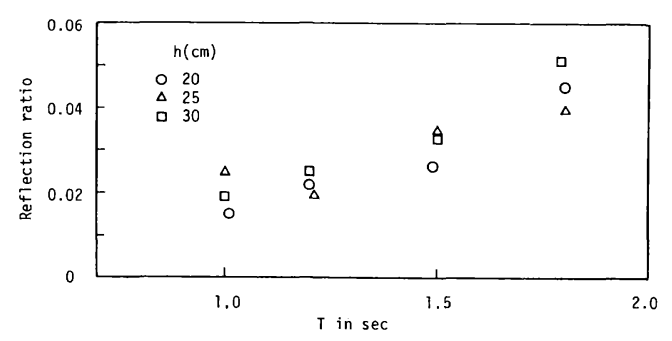

Fig. 11 Reflection ratio at the end of wave flume.

成されている観測域 (長さ $4 \mathrm{~m}$ ) を通過する際の波の透 過率 $R_{t}$ および反射率 $R_{r}$ を知る必要があるが, これら の計算は以下の方法によった. これらの波高計によって 記録される波形が正弦波で十分近似できることを確かめ たうえで, 入射波, 反射波, 透過波およびその反射波 (前 述のように，ごくわずかではあるが水路端から反射があ る) を次のように置く.

$\begin{array}{ll}\text { 入射波: } & y=A \sin \left(\sigma t+k x+\phi_{A}\right) \cdots \cdots \cdots(34 \cdot \mathrm{a}) \\ \text { 反射波： } & y=B \sin \left(\sigma t-k x+\phi_{B}\right) \cdots \cdots \cdots(34 \cdot \mathrm{b}) \\ \text { 透過波: } & y=C \sin \left(\sigma t+k x+\phi_{C}\right) \cdots \cdots \cdots(34 \cdot \mathrm{c}) \\ \text { その反射波 }: & y=D \sin \left(\sigma t-k x+\phi_{D}\right) \cdots \cdots \cdots(34 \cdot \mathrm{d})\end{array}$ ここに, $A, B, C, D$ は振幅, $\phi_{A}, \phi_{B}, \phi_{C}, \phi_{D}$ は位相 を表わす.このとき, Fig. 10 に示される岸側の波高計 1 , 2 に記録される波を次のように置く.

波高計 $1: y=A_{1} \cos \sigma t+B_{1} \sin \sigma t$

波高計 $2: y=A_{2} \cos \sigma t+B_{2} \sin \sigma t$ $(35 \cdot b)$ 
ここに, $A_{1}=C \sin \phi_{C}+D \sin \phi_{D}, \quad B_{1}=C \cos \phi_{C}+D$ $\sin \phi_{D}, A_{2}=C \sin \left(k x_{1}+\phi_{C}\right)+D \sin \left(-k x_{1}+\phi_{D}\right), \quad B_{2}=$ $C \cos \left(k x_{1}+\phi_{C}\right)+D \cos \left(-k x_{1}+\phi_{D}\right)$ であり, $x$ 方向 の原点は波高計 1 にとり，波高計 2 は $x_{1}$ だけ離れてい る。これから， $C, D$ の値は

$$
\begin{aligned}
& C=\left\{\left[\left(A_{1}+M\right) / 2\right]^{2}+\left[\left(B_{1}+N\right) / 2\right]^{2}\right\}^{1 / 2} \\
& D=\left\{\left[\left(A_{1}-M\right) / 2\right]^{2}+\left[\left(B_{1}-N\right) / 2\right]^{2}\right\}^{1 / 2}
\end{aligned}
$$

となる.ここに, $M=\left(B_{1} \cos k x_{1}-B_{2}\right) / \sin k x_{1}, N=$ $\left(A_{2}-A_{1} \cos k x_{1}\right) / \sin k x_{1}$ である. 同様にして, 沖側の 波高計 3,4 について, 波高計 3 を新たな $x$ 方向の原点 として次式が導かれる.

$$
\begin{aligned}
& A=\left\{\left[\left(A_{3}+I\right) / 2\right]^{2}+\left[\left(B_{3}+J\right) / 2\right]^{2}\right\}^{1 / 2} \\
& B=\left\{\left[\left(A_{3}-I\right) / 2\right]^{2}+\left[\left(B_{3}-J\right) / 2\right]^{2}\right\}^{1 / 2}
\end{aligned}
$$

ここに, $I=\left(B_{3} \cos k x_{2}-B_{4}\right) / \sin k x_{2}, \quad J=\left(A_{4}-A_{3}\right.$ $\left.\cos k x_{2}\right) / \sin k x_{2}$ であり， $x_{2}$ は波高計 4 の位置である. したがって, 以上から透過率 $R_{t}$, 反射率 $R_{r}$ は以下の ようになる。

$$
\begin{aligned}
& R_{t}=\frac{C}{A}=\left[\frac{\left(A_{1}+M\right)^{2}+\left(B_{1}+N\right)^{2}}{\left(A_{3}+I\right)^{2}+\left(B_{3}+J\right)^{2}}\right]^{1 / 2} \\
& R_{r}=\frac{B}{A}=\left[\frac{\left(A_{3}-I\right)^{2}+\left(B_{3}-J\right)^{2}}{\left(A_{3}+I\right)^{2}+\left(B_{3}+J\right)^{2}}\right]^{1 / 2} .
\end{aligned}
$$

よって，4 $\mathrm{m}$ 区間の波のエネルギー逸散率 $P$ は

$$
P=1-R_{t}^{2}-R_{r}^{2}
$$

となる．以上の測定を砂漣形成前の平坦床，砂漣が完全 に発達した後について行い, それぞれのエネルギー逸散 率を $P_{f}, P_{t}$ とすると, 砂漣の渦による逸散率 $P^{\prime}$ は

$$
P^{\prime}=P_{t}-P_{f}
$$

となる。

このような波高測定を終了した後，測定区間の $1 \mathrm{~m}$ について，砂漣の波高と波長をそれぞれポイント・ゲー ジと定規を用いて測定した。この結果を本間・堀川尚が 提案した式と比較したところ，よく一致した。ささらに， 1 砂漣当たりのエネルギー逸散率を求めるために, 観測 区間 $4 \mathrm{~m}$ の間の砂漣の個数を数えた. この個数を $N_{r}$ と すると, 1 砂漣当たりの波のエネルギー逸散率 $P_{w}$ は

$$
P_{w}=P^{\prime} / N_{r}
$$

となる，この $P_{w}$ が式 $(29)$ によって表わされる $P_{v}$ に 対応するものである.

実験条件は Table 4(a) に示しているが，水深は 20, $25,30 \mathrm{~cm}$ の 3 種類とし, それぞれの水深について周期 を約 $1 ， 1.2 ， 1.5$ 秒に変化させた. それぞれの条件下の

\begin{tabular}{|c|c|c|c|c|c|c|c|c|c|}
\hline Run & $\begin{array}{l}v \times 10^{2} \\
\left(\mathrm{~cm}^{2} / \mathrm{s}\right)\end{array}$ & $\begin{array}{c}\mathrm{h} \\
(\mathrm{cm})\end{array}$ & $\begin{array}{l}\mathrm{H} \\
(\mathrm{cm})\end{array}$ & $\begin{array}{c}\mathrm{L} \\
(\mathrm{cm})\end{array}$ & $\begin{array}{c}T \\
(s)\end{array}$ & $\begin{array}{c}\mathrm{Hr} \\
(\mathrm{cm})\end{array}$ & $\begin{array}{c}\mathrm{Lr} \\
(\mathrm{cm})\end{array}$ & $\begin{array}{c}\mathrm{Pv} \\
\times 10^{3}\end{array}$ & $\begin{array}{c}P_{W} \\
\times 10^{3}\end{array}$ \\
\hline 2047 & 1.24 & 20 & 5.464 & 120 & .992 & 0.61 & 3.48 & 1.08 & .48 \\
\hline 2036 & 1.22 & 20 & 5.466 & 120 & 0.992 & 0.64 & 3.54 & 1.07 & .43 \\
\hline 2037 & 1.1 & 20 & 148 & 123 & 1.011 & 0.66 & 3.66 & 1.21 & .48 \\
\hline 2039 & & 20 & & 121 & 0.999 & 0.67 & 3.80 & 1.27 & 46 \\
\hline 2040 & & 20 & & 151 & 1.191 & 0.72 & 3.85 & 1.18 & 48 \\
\hline 2041 & & 20 & & 150 & 1.185 & 0.76 & 4.05 & & 10 \\
\hline 2042 & & 20 & & & 1.185 & 0.79 & 4.29 & 43 & 62 \\
\hline 2043 & & 20 & & 190 & 1.450 & 0.82 & 4.34 & & .730 \\
\hline 2044 & & 20 & & 190 & 1.450 & 0.91 & 4.51 & & .783 \\
\hline 2048 & & & & & 1.470 & 0.87 & 4.82 & & .04 \\
\hline 2057 & & 20 & & 213 & 1.605 & 0.98 & 4.66 & 47 & .95 \\
\hline 2511 & & 25 & & 132 & 1.009 & 0.60 & 3.34 & 0.727 & 43 \\
\hline 2517 & & 25 & & & 0.998 & 0.60 & 3.78 & & 16 \\
\hline 2549 & & 2 & & & 1.015 & 0.63 & 3.6 & & 24 \\
\hline 2550 & & & & & 0.998 & 0.65 & 3.8 & 837 & 34 \\
\hline 2514 & & & & & 1.223 & 0.66 & 3. & 766 & 47 \\
\hline 2515 & & & & & 1.178 & 0.68 & 3.7 & 34 & 51 \\
\hline 2516 & & & & & 1.178 & 0.78 & 4. & & 52 \\
\hline 2518 & & & & & 1.457 & 0.89 & 4.3 & 990 & 47 \\
\hline 2519 & & & & & 1.480 & 0.87 & 4. & & S \\
\hline 2520 & & 25 & & & 1.498 & 0.93 & 4. & & 65 \\
\hline 3021 & & 30 & & & 0.999 & 0.59 & 3.3 & 465 & \\
\hline & & & & & 1.009 & 0.61 & 3. & 155 & 17 \\
\hline & & & & & 999 & 0.60 & 3. & & $2^{2}$ \\
\hline 305 & & & & 13 & 0.999 & 0.54 & 3. & 186 & .36 \\
\hline & & & & & 1.190 & 0.71 & 3. & 586 & .34 \\
\hline & & & & 175 & 1.190 & 0.77 & 4.0 & 0.649 & .4 \\
\hline & & & & 175 & 1.190 & 0.74 & 4.1 & 0.679 & .1 \\
\hline & & & & 233 & 1.490 & 0.89 & 4.58 & 0.723 & .39 \\
\hline 305 & & & & 235 & 1.500 & 0.87 & 4.52 & 0.713 & .30 \\
\hline 302 & & & & 221 & 1.430 & 0.92 & 4.75 & 0.724 & .25 \\
\hline 3053 & & & & 231 & 1.480 & 0.94 & 4.86 & 0.802 & .3 \\
\hline 3054 & 1.18 & 30 & 7.103 & 227 & 1.460 & 0.96 & 5.12 & 0.855 & \\
\hline
\end{tabular}
波高 $H$, 波長 $L$, 砂漣の波高 $H_{r}$, 波長 $L_{r}$, エネルギ一 逸散率 $P_{w}$ も Table 4(a) に示されている。.また，これ らの水理量を用いて式 $(29)$ 加計算される $P_{v}$ の值も 揭載した. $P_{v}$ の計算に際して必要な $\delta, \delta^{\prime \prime}, \lambda$ の值は Table 4(b) のように求められている.

Fig. 12 は以上のようにして得られた $P_{v}$ (予測值) と

\section{Table 4}

(a) Summary of wave flume tests

(b) Values of $\delta, \delta^{\prime \prime}$ and $\lambda$ used in calculating $P_{v}$

\begin{tabular}{|c|c|c|c|}
\hline$T(\mathrm{~s})$ & $\delta(\mathrm{cm})$ & $\delta "$ & $\lambda$ \\
\hline$T<1.1$ & 0.114 & -0.019 & 1.61 \\
$1.15<\mathrm{T}<1.25$ & 0.122 & -0.020 & 1.60 \\
$1.4<\mathrm{T}$ & 0.136 & -0.022 & 1.58 \\
\hline
\end{tabular}

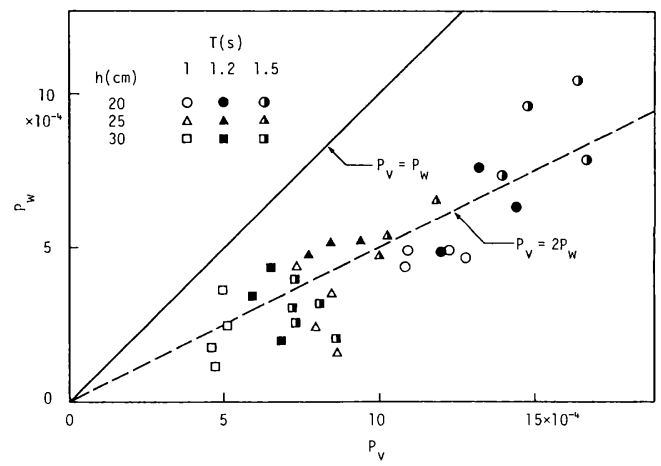

Fig. 12 Comparison of $P_{v}$ and $P_{w}$.

$P_{w}$ (実測値) を比較したものである. この図から $P_{v}$ と $P_{w}$ はよい線形関係を満たすことが知られ,式(29)によっ て表現されている関数関係が妥当であることがわかる. 
しかし， $P_{v}$ は $P_{w}$ の 2 倍程度の值を与えており，この 理由はFig. 8，9で説明したように渦の循環の見積りに あると考えられる. Fig. 8 に示されるように, 式 (22) から予測される循環値は実測値の約 1.4 倍となってい る.ところが，渦によるエネルギー逸散は式（25）に示 されるように循環の二乗に比例するので, エネルギー逸 散は $(1.4)^{2} \fallingdotseq 2$ となり， $P_{v}$ が $P_{w}$ の 2 倍程度となるこ とを説明できる. Fig. 9 において明らかにされたように, 式（22）が循環值を大きく見積る原因は $\hat{u}_{n}$ の值，すな わち $\lambda=\hat{u}_{n} / \hat{U}$ の值を実際の值よりも大きく見積ること にあった.このことは砂漣近傍の境界層の特性およびそ の結果としての流速分布と深くかかわりあっており, エ ネルギー逸散量をより正確に見積るには底面近傍の流速 分布をより詳細に研究し, 定式化する必要があろう.な お，本研究ではこれまで述べた方法によって計算された $\lambda$ の值 (Table 4(b) 参照)，1.6 程度を用いて式 (29) から $P_{v}$ を計算しているが， $P_{v}$ と $P_{w}$ が一致するために は $\lambda=1.6 / 1.4 \fallingdotseq 1.14$ とすればよい.この $\lambda$ の值は剝離 渦によって境界層およびその近傍がよく混合させられて

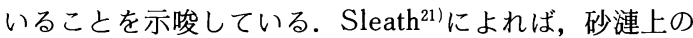
境界層は $H / L_{r} \leqq 0.2$ で層流， $H / L_{r}=0.4$ 程度で遷移領 域, $H / L_{r} \geqq 0.6$ で完全に発達した乱流域となるとして いるが, 本実験条件では最小の $H / L_{r}$ は0.91(Run 2057) であり,やはり砂漣近傍の境界層流れが乱流となってい ることが知られる。

\section{5. 結 論}

本研究では, まず砂漣背後に形成される剝離渦に関し てポテンシャル流理論を応用して循環を求める理論式を 得, これを人工砂漣を用いた振動流実験により確かめた. さらに，この剝離渦のもつ運動エネルギ一が波のエネル ギ一逸散になるとして，波のエネルギ一逸散率を表わす 式を波の波高・波長, 水深などの外部変量の関数として 求め, この理論式を二次元造波水路で砂漣を発生させ, 波のエネルギー逸散を測定することにより確かめた。以 上の研究により以下の点が明らかとなった。

（1）剝離渦の循環はポテンシャル流れに境界層を導 入し, Kuttaの条件を砂漣頂部に適用することにより見 積りが可能である．境界層厚さや砂漣近傍の流速分布を 見積ることが循環の計算上必要となるが，このとき境界 層が層流であるか乱流であるかにより流速分布等が異な ることに注意する必要がある.

( 2 ）剝離渦内の流速や循環の分布はOseen 渦型の 分布によってよく表現される.

（３）剝離渦の循環の最大值は流速の最大値の位相よ りも遅れて出現し, その位相差は振動流の周期が長くな るほど大きくなる.
（4）砂漣による波のエネルギー逸散率を渦のもつ運 動エネルギーが最終的に波のエネルギ一逸散になるとし て導かれた理論式と比較したところ，両者は大変よい線 形関係を示したが，定量的には理論式の方が測定值の約 2 倍の値を示した.この理由は（1）で述べたように砂 漣上の境界層が本実験条件では乱流境界層となっていた ために, 循環值を実際の值の約 1.4 倍程度に見積ったこ とにあると考えられる.

（5）今後, 砂漣上の乱流境界層をより詳細に把握す る必要があり，これにより波のエネルギ一逸散や浮遊砂 の巻き上げ量をより正確に見積ることができる.

謝辞：本研究の遂行にあたっては, 埼玉大学堀 川清司教授からさまざまな助言を頂いた。また，同大学 中村広昭助手には実験に際して援助を頂いた。記して謝 意を表します。

1) Bagnold, R. A. : Motion of waves in shallow water; Interaction between waves and sand bottoms, Proc. Roy. Soc. London, A 187, pp. 1 18, 1946.

2）本間 仁・堀川清司・鹿島遼一：波による浮遊砂に関す る研究, 第 11 回海岸工学講演会講演集, pp. 159 168, 1964.

3) Hom-ma, M. and Horikawa, K. : Suspended sediment due to wave action, Proc. 8 th Conf. on Coastal Eng., pp. 168 193, 1963.

4) Carstens, M. R., Nielson, F. M. and Altinbilek, H. D. : Bed forms generated in the laboratory under oscillatory flow, Coastal Engrg. Res. Center, Fort Belvoir, Va., Tech. Mem, No. 28, 1969.

5) Nielsen, P. : Dynamics and geometry of wave-generated ripples, J. Geophys. Res., Vol.86, No. C 7, pp.6467 6472, 1981.

6) Horikawa, K. and Watanabe, A. : Laboratory study on oscillatory boundary layer flow, Proc. 11th Conf. on Coastal Eng., pp. 467 486, 1968.

7) Kajiura, K. : On the bottom friction in an oscillatory current, Bull. Earthquake Res. Inst., Univ. of Tokyo, Vol. 42, 1968.

8) Tunstall, E. B. and Inman, D. L. : Vortex generation of oscillatory flows over rippled surfaces, J. Geophys. Res., Vol. 80, No. 24, pp. 3475 3484, 1975.

9）沢本正樹・山口清一：進行波による砂漣上の境界層内の 流速及び乱れ分布, 第 25 回海岸工学講演会論文集, pp. $46 \sim 50,1978$.

10）沢本正樹・山口清一：波によって生じる砂漣近くの流れ のモデル化と浮遊砂濃度の算定法, 土木学会論文報告集, 288 号, pp. 107 113, 1979.

11）沢本正樹・山下俊彦・山口修一：拡大相似模型を用いた 砂漣上の振動流の測定, 東工大土木工学科研究報告, 31 号, pp. 157 168, 1983. 
12) Sawamoto, M., Yamashita, T. and Kurita, T. : Vortex formation over rippled-bed under oscillatory flow, Tech. Rep., No.27, Dept. of Civil Eng., Tokyo Inst. of Technology, pp. 75 85, 1980.

13) Shibayama, T. and Horikawa, K. : Laboratory study on sediment transport mechanism due to wave action, 土木学会論文報告集, 296 号, pp. 131 141， 1980.

14) Du Toit, C. G. and Sleath, J.F. A. : Velocity measurements close to rippled beds in oscillatory flow, J. Fluid Mech., Vol.112, pp.71 96, 1981.

15) Longuet-Higgins, M.S. : Oscillating flow over steep sand ripples, J. Fluid Mech., Vol. 107, pp. 1 35, 1981.

16) Sato, S. and Horikawa, K. : Laboratory study on sand transport over ripples due to asymmetric oscillatory flows, Proc. 20th Coastal Eng. Conf., ASCE, pp. 1481 $\sim 1495,1986$.

17) Sato, S., Uehara, H. and Watanabe, A. : Numerical simulation of the oscillatory boundary layer flow over ripples by a $k-\varepsilon$ turbulence model, Coastal Eng. in Japan, Vol.29, pp.65〜78, 1986.

18）たとえば, 谷 一郎：流体力学の進歩境界層, 丸善, 1984.

19) Blevins, R. D. : Flow-induced vibration, Van Nostrand, p. 18, 1977.

20）池田駿介・浅枝 隆・野本健司・木村恵利子：波動場に 置かれた垂直板付近の発生渦の特性とエネルギー逸散, 土木学会論文集, 363 号, pp. 87 96, 1985.

21) Sleath, J.F.A. : Velocities above a rough bed in oscillatory flow, J. WW Div., Vol.100, No. WW 4, pp. $287 \sim 304,1974$

(1988.8.1 • 受付) 